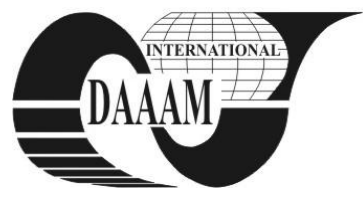

Annals of DAAAM for 2011 \& Proceedings of the 22nd International DAAAM Symposium, Volume 22, No. 1, ISSN 1726-9679 ISBN 978-3-901509-83-4, Editor B. Katalinic, Published by DAAAM International, Vienna, Austria, EU, 2011 Make Harmony between Technology and Nature, and Your Mind will Fly Free as a Bird Annals \& Proceedings of DAAAM International 2011

\title{
MULTIDISCIPLINARY EVALUATION OF COMPLETE DENTURES DURABILITY
}

\author{
BORTUN, C[ristina] M[aria] \& CERNESCU, A[nghel]
}

\begin{abstract}
The objective of this study was focused on fracture resistance evaluation of dentures, in the presence of of some structural defects. There were used complete dentures, achieved by 2 technologies, from different materials with structural defects. Finite element analysis was made on geometric models and image processing by, "reverse engineering'. By numerical simulation (FEM-XFEM) one revealed the stress and strain areas that appear on dentures subjected to force loading. For fracture strength evaluation of the complete denture, one used Fracture Mechanics concepts and calculated the stress intensity factors for different located cracks and defects.The defects in the material's structure may have a negative impact on denture's mechanical resistance.

Key words: complete denture, FEM-XFEM, defects, mechanical resistance
\end{abstract}

\section{INTRODUCTION}

Generally, the complete dentures bases are made of acrylic resins - heat curing, light curing technologies. Processing technology of these materials sometimes lead to complete dentures with small defects, which can initiate cracks; these are responsible for failure of the complete denture before the expected lifetime. The selection of materials used in complete dentures technology is crucial, because this directly relates to its performance and life span. The relative short lifetime of the complete dentures has led researchers to investigate the causes of fracture by studying the stress distribution (Cheng et al., 2010; Pandurić et al., 1998) upon mastication and to find ways to improve their mechanical performance. The finite element method (FEM) has been used for five decades for numerical stress analysis (Faur, 2002). Extended Finite Element Method (XFEM) (Giner et al., 2009; Waisman, 2010; Abdelaziz \&Abdelmadjid, 2008; Elguedj et al.,2009; Lu\&Liu, 2010;Rees et al.,1990), is a procedure incorporated in ABAQUS, used to determine whether to applied load, a crack is initiated or not, where it appears and the stress intensity factors at the crack tip. The aims of this paper were to investigate the stress distribution and structural integrity of a maxillary complete denture based on a proposed methodology involving FEM analysis, a thorough knowledge of the mechanical properties of the material and good knowledge of Fatigue and Fracture Mechanics.

The multidisciplinary study of dentures is used for knowledge of risk zone for fracture and for garanty a complete denture with structural defects.

\section{MATERIALS AND METHODS}

One selected five pairs of complete dentures, achieved with 2 technologies, from different materials: heat-curing materialMeliodent (Heraeus Kulzer, Senden, Germany) and light-curing material- Eclipse Resin System (Dentsply International Inc.DeguDent GmbH, Hanau Germany). The nondestructive evaluation of the dentures was realized with Olympus stereomicroscope, Type SZX7, locating the defects and microcracks resulted from their technology. The mechanical properties of the materials were determined by experimental tests, with Zwick Roell equipment (Zwick GmbH \& Co. KG, Ulm, Germany). Based on this tests performed according to ISO 527 (tensile tests) and ASTM D 790 (bending tests) standard, one evaluated the materials'mechanical properties. Finite element analysis was made on geometric models, resulted after the complete dentures' 3D scanning (with 3D laser scanner LPX1200, Roland pitch of $0.1 \times 0.1 \mathrm{~mm}$ ) and image processing by ,reverse engineering”, taking into consideration the located defects (software: Abaqus/CAE V6.9). The hollow denture was exported in initial graphics exchange specification (IGES) format and then imported into Solid Works 2007 for conversion into a solid model (Fig. 1.a). Using the FEM software package, ABAQUS v6.9.3, on the geometric model of the upper complete denture one determined the stress and strain state for a static pressure of $1.5 \mathrm{MPa}$ applied on the support cusps (fig. 1.a). The geometric model was meshed in tetrahedral finite elements, C3D8 (154742 elements) and based on FEM simulation, one determined the Maximum Principal Stress (Fig. 1.c) and Maximum Principal Strain (Fig. 1.d).

\section{RESULTS AND DISCUSSION}

The mechanical properties resulted after the experimental programs were: Eclipse Base Plate (Ultimate Tensile Strength: $\sigma_{\text {uts }}=69.92 \mathrm{MPa}$, Tensile Young's modulus: $\mathrm{E}=2900 \mathrm{MPa}$, Total Elongation: $A_{t}=4.58 \%$, Flexural Strength: $\sigma_{\mathrm{f}}=92 \mathrm{MPa}$ ); Meliodent (Ultimate Tensile Strength: $\sigma_{\text {uts }}=65.8 \mathrm{MPa}$, Tensile Young's modulus: $\mathrm{E}=1168 \mathrm{MPa}$, Total Elongation: $\mathrm{A}_{\mathrm{t}}$ $=8.32 \%$, Flexural Strength: $\sigma_{\mathrm{f}}=81.4 \mathrm{MPa}$. The fracture toughness was determined based on critical stress intensity factor, $\mathrm{K}_{\mathrm{c}}$, on SENB samples, according to ASTM D 5045 standard). Thus, fracture toughness was evaluate as $\mathrm{K}_{\mathrm{IC}}=$ 100.655 $\mathrm{MPa} \sqrt{\mathrm{mm}}$ for Eclipsed Base Plate and $\mathrm{K}_{\mathrm{IC}}=75.95$ $\mathrm{MPa} \sqrt{\mathrm{mm}}$ for Meliodent. Using XFEM procedure, one can evaluate the values of stress intensity factors at the crack tip, to determine an equivalent stress intensity factor, $K_{I}^{e q}$, and compare with fracture toughness, $\mathrm{K}_{\mathrm{IC}}$. According to XFEM procedure, in order to evaluate the stress intensity factors $\mathrm{K}_{\mathrm{I}}$ and $\mathrm{K}_{\mathrm{II}}$, one must identify the elements that contain the crack and the crack-tip nodes (fig. 2). For these nodes the nodal displacements are recalculated with the following relationship:

$$
\begin{aligned}
& u_{X F E M}(x)=\sum_{i \in \Gamma} N_{i}(x) u_{i}+\sum_{i \in \Lambda} N_{i}(x) H(x) a_{i}+\sum_{i \in \mathrm{K}}\left[N_{i}(x) \sum_{\alpha=1}^{4} F_{\alpha}(x) b_{i \alpha}\right] \\
& {\left[F_{\alpha}(r, \theta), \alpha=1-4\right]=\left[\sqrt{r} \sin \frac{\theta}{2}, \sqrt{r} \cos \frac{\theta}{2}, \sqrt{r} \sin \frac{\theta}{2} \sin \theta, \sqrt{r} \cos \frac{\theta}{2} \sin \theta\right]}
\end{aligned}
$$

where $\Gamma$ is the set of all nodes in the mesh, $\mathrm{N}_{\mathrm{i}}(\mathrm{x})$ is the nodal 
shape function and $u_{i}$ is the standard DOF of nodes $i\left(u_{i}\right.$ represents the physical nodal displacement for non-enriched nodes only). The subsets $\Lambda$ and $\mathrm{K}$ contain the nodes enriched with Heaviside function $\mathrm{H}(\mathrm{x})$ or crack-tip functions $\mathrm{F}_{\alpha}(\mathrm{x})$, respectively, and $\mathrm{a}_{\mathrm{i}}, \mathrm{b}_{\mathrm{i} \alpha}$ are the corresponding DOFs, and $\mathrm{r}, \theta$ are local polar co-ordinates defined at the crack tip.

Once the nodal displacements for the crack-tip nodes was obtained with XFEM procedure and the post-processing subroutines, adapted for our case, applied, one obtained values of stress intensity factors $\mathrm{K}_{\mathrm{I}}$ and $\mathrm{K}_{\mathrm{II}}$ and the $K_{I}^{e q}$ :

$$
\begin{gathered}
\theta_{c}=2 \tan ^{-1}\left[\frac{1}{4}\left(\frac{K_{I}}{K_{I I}}+\operatorname{sign}\left(K_{I I}\right) \sqrt{8+\left(\frac{K_{I}}{K_{I I}}\right)^{2}}\right)\right] \\
K_{I}^{e q}=K_{I} \cos ^{3}\left(\frac{\theta_{c}}{2}\right)-\frac{3}{2} K_{I I} \cos \left(\frac{\theta_{c}}{2}\right) \sin \theta_{c}
\end{gathered}
$$
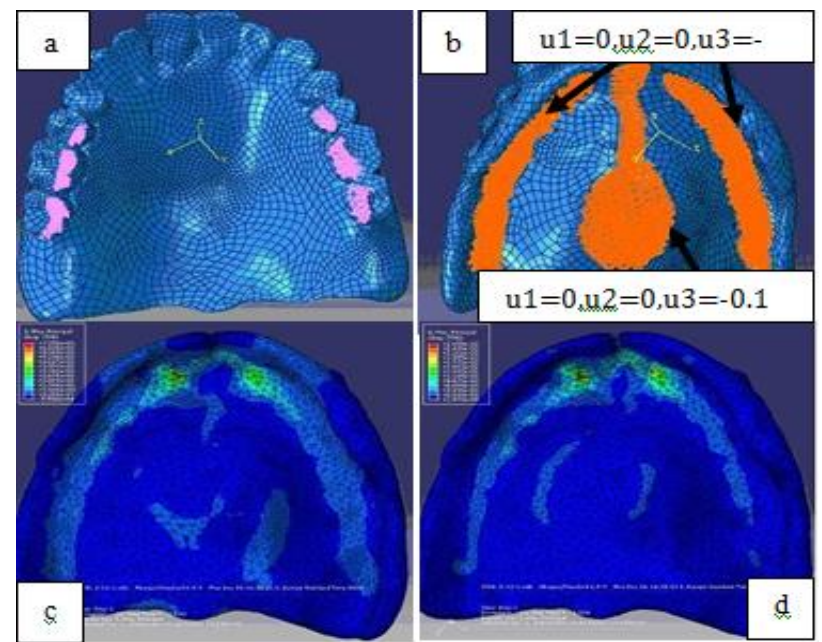

Fig. 1. a. The applied pressure on palatal cusps; b. applied boundary conditions on the teeth teeth of upper complete denture; c. the Maximum Principal Stress distribution (Max. value is $72.5 \mathrm{MPa})$; d. the Maximum Principal Strain distribution (Max. value is $0.0265 \mathrm{~mm} / \mathrm{mm}$ )

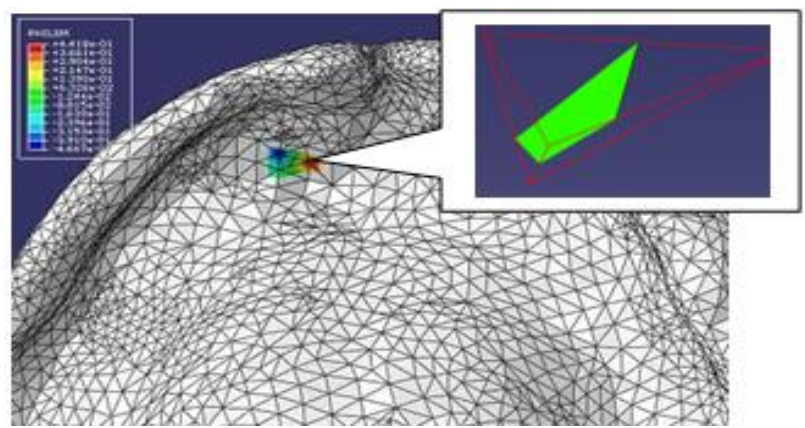

Fig. 2. The Heaviside functions of enriched nodes, the enriched element and crack location (medallion)

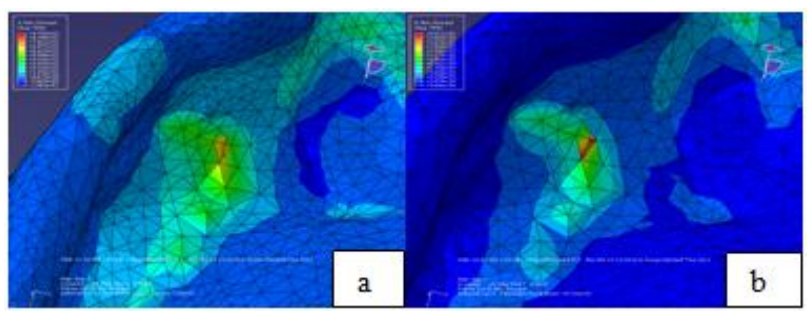

Fig. 3. The Maximum Principal Stress (a) and Strain (b) distribution for Meliodent denture
This study is focused on evaluation of mechanical strength of dental prosthetic structures using a method that requires a thorough knowledge of material characteristics and a good knowledge of the concepts of Fracture Mechanics and FEM analysis, Damage Tolerance Approach. This analysis can be used for strength calculations of dentures that are in design stage and for those that are in use and after the examination one observed defects or cracks.

\section{CONCLUSION}

Complete dentures' defects can initiate cracks that are responsible for their failure before the expected lifetime. Study of the denture's mechanical properties by finite element analysis is used for knowledge of risk zone for fracture.

\section{ACKNOWLEDGEMENTS}

This study was financial supported by IDEAS GRANT of National University Research Council \& Ministry of Education and Research of Romania, ID 1878/2008 and contract $1141 / 2009$ and by the project PERFORM ERA ID-57649, contract POSDRU/89/1.5/S/57649, from the Ministry of Education and Research of Romania.

\section{REFERENCES}

Yi Y Cheng, Wai L Cheung and Tak W Chow: Strain analysis of maxillary complete denture with three-dimensional finite element method, Journal of Prosthetic Dentistry, Volume 103, Issue 5 , Pages 309-318, May 2010, ISSN 00223913

Pandurić J, Husnjak M, Guljas K, Kraljević K, Zivko-Babić J.: The simulation and calculation of the fatigue of the lower complete denture in function by means of the finite element analysis. J.Oral Rehabil. 1998 Jul;25(7):560-5, PrintISSN:0305-182X,Online ISSN: 1365-2842

Faur N.: Finite elements - fundamentals, Politehnica Publishing House, Timisoara, 2002, ISBN: 973-8247-98-5

E. Giner, N. Sukumar, Tarancon J.E., Fuenmayor FJ.: An Abaqus implementation of the extended finite element method', Engineering Fracture Mechanics,76:347-368, 2009, ISSN: 0013-7944

Waisman H.: An analytical stiffness derivative extended finite element technique for extraction of crack tip Strain Energy Release Rate, Eng. Fracture Mechanics, 77:3204-3215, 2010, ISSN: 0013-7944

Abdelaziz Y, Abdelmadjid H.: A survey of the extended finite element, Computers and Structures, 86: 1141-1151, 2008, ISSN: 0045-7949

Elguedj T, Gravouil A, Maigre H.: An explicit dynamics extended finite element method. Part I: Mass lumping for arbitrary enrichment functions, Comput. Methods Appl. Mech. Eng., 198:2297-2317, 2009, ISSN: 0045-7825

Elguedj T, Gravouil A, Maigre H.: An explicit dynamics extended finite element method. Part II: Element-byelement stable-explicit/explicit dynamic scheme, Comput. Methods Appl. Mech. Eng., 198: 2318-2328, 2009, ISSN: 0045-7825

Zizi Lu, Yongming Liu.: Concurrent fatigue crack growth simulation using extended finite element method, Fron. Archit. Civ. Eng. China, 4(3): 339-347, 2010, ISSN : 16737407 (print), 1673-7512 (electronic)

***Rees Js, Huggett R, Harrison A.: Finite element analysis of the stress-concentrating effect of fraenal notches in complete dentures. Int J Prosthodont, 3:238-40, 1990, ISSN: 0893-2174 